\title{
ERRATUM
}

\section{Prenatal stress and the developing brain: Risks for neurodevelopmental disorders — ERRATUM}

\section{BEA R. H. VAN DEN BERGH, ROBERT DAHNKE, AND MAARTEN MENNES}

doi:10.1017/S0954579418000342, published by Cambridge University Press, 2 August 2018

In the original publication of this article (Van den Bergh, Dahnke, \& Mennes, 2018) author Bea Van den Bergh's name was incorrectly capitalized. In addition, the correct second affiliation for author Van den Bergh is Department of Welfare, Public Health and Family, Flemish Government, Brussels, Belgium. With regard to the incorrect capitalization, the article has since been corrected.

\section{Reference}

Van den Bergh, B. R. H., Dahnke, R., \& Mennes, M. (2018). Prenatal stress and the developing brain: Risks for neurodevelopmental disorders. Development and Psychopathology, 30, 743-762. doi:10.1017/ S0954579418000342 